\title{
AS DIRETIVAS ANTECIPADAS DE VONTADE E O FILME MAR ADENTRO: UM DIÁLOGO COM A AUTONOMIA PRIVADA DO INDÍVIDUO
}

\author{
Francislaine de Almeida Coimbra Strasser, Cleberson Aparecido de Morais Silva, Andre Soares Sartoro \\ Universidade do Oeste Paulista - UNOESTE, Presidente Prudente, SP.E-mail: fran coimbra@ @ hotmail.com
}

\begin{abstract}
RESUMO
O artigo trata acerca da importância das Diretrizes Antecipadas de Vontade, nas modalidades de testamento vital e mandamento duradouro, como instrumentos de tutela do direito à morte digna enfeixada na autonomia da vontade do paciente, respeitando-a nos momentos em que estiver impossibilitado de exercê-la. Para tanto, enfatiza-se a necessidade de o operador do direito estar conectado aos avanços da medicina, e imprimir segurança jurídica aos profissionais de saúde para não responderem judicialmente, pelos resultados concretizados e para que façam cumprir a manifestação do paciente exteriorizada em qualquer um dos referidos documentos ante a possíveis conflitos com a vontade dos familiares. Por isso, defende-se a necessidade de se lavrar escritura pública em Cartório de Notas sobre essa manifestação de vontade. Também se enfatizou a revogabilidade desse documento, que encontra limites nas disposições do Código de Ética Médica. O método utilizado na presente pesquisa foi o dedutivo, qualitativo, partindo da premissa geral sobre a intocabilidade do direito à vida para a absorção do instrumento Diretivas Antecipadas de Vontade no direito, que deve se curvar à oportunização de caminhos que se levem ao reconhecimento da dignidade da pessoa humana, no momento final da vida do paciente.
\end{abstract}

Palavras-chave: Morte; Diretrizes Antecipadas de Vontade; Dignidade da Pessoa Humana.

\section{ANTICIPATED WILL DIRECTIVES AND THE FILM IN MAR ADENTRO: A DIALOGUE WITH THE PRIVATE AUTONOMY OF THE INDIVIDUAL}

\begin{abstract}
The article deals with the importance of the Advance Will Directives, in the modalities of living will and lasting commandment, as instruments of protection of the right to a dignified death bundled in the autonomy of the patient's will, respecting it in moments when it is impossible to exercise it. there. Therefore, it emphasizes the need for the operator of the law to be connected to medical advances, and provide legal certainty for health professionals not to respond in court, for the results achieved and to enforce the patient's manifestation expressed in any of these documents in view of possible conflicts with the will of the family. Therefore, we defend the need to draw up a public deed in the Notary Public on this expression of will. The revocability of this document was also emphasized, which is limited by the provisions of the Code of Medical Ethics. The method used in this research was the deductive, qualitative one, based on the general premise about the untouchability of the right to life for the absorption of the instrument Anticipated Directives of Will in law, which should bend to the opportunity of paths that lead to the recognition of dignity of the human person, at the end of the patient's life.
\end{abstract}

Keywords: Death; Advance Will Directives; Dignity of human person. 


\section{INTRODUÇÃO}

A Medicina atual à medida que vai avançando em técnicas para salvar vidas fica cada mais difícil definir o fim da existência humana, sobretudo quando se conflita a situação delicada da morte com do paciente terminal ou de alguma doença que ainda não tenha cura, qual seja a preservação da vida com o alívio do sofrimento.

O presente trabalho visa tratar sobre a morte, que é sempre um "tabu" porque as pessoas não estão preparadas para enxergar a terminalidade da vida, mesmo sabendo que esse fim se concretizará. Geralmente não há um planejamento sobre o falecimento, sobre as disposições de última vontade.

Daí a importância em discorrer sobre as Diretivas Antecipadas de Vontade, que é um instrumento de efetivação da autonomia privada do indivíduo, pois se deve respeitar os atos exteriorizados e os desejos do indivíduo no momento em que não pode mais manifestar suas vontades.

Verifica-se que apesar de não existir dispositivo legal que discipline sobre o instituto, 0 Conselho Federal de Medicina regulamentou sobre, com a Resolução 1.995/2012, em que a vontade do paciente prevalece sobre a dos familiares, dialogando com o fundamento da República, a dignidade da pessoa humana, pois nesse instrumento deve conter os valores que fundam as decisões do paciente, e seus desejos no intuito de orientar a equipe médica no que deve ser realizado.

Percebe-se que além de dialogar com o fundamento da República, o artigo 5으. III da Carta Maior proíbe o tratamento desumano ou degradante; o Código Civil, em seu artigo 15 dispõe sobre a vedação de imposição de tratamento médico, contrariando a vontade do paciente e a $\mathrm{V}$ Jornada de Direito Civil do Conselho Federal de Medicina, impõe em seu Enunciado 528 acerca da validade e eficácia que imprime a disposição do paciente em testamento vital.

Assim, por ser um instituto de grande valia, se interrelacionou com o filme Mar Adentro, que conta a história de um espanhol Ramón Sampedro, que lutou pelo direito de conseguir a sua liberdade, aprisionada em um corpo morto, sendo que apesar de não ter conseguido o salvo conduto de um profissional médico realizar a eutanásia, se suicidou com a ajuda de sua namorada.
Partindo dessas premissas introdutórias, o presente trabalho pretende a partir de uma pesquisa qualitativa, valendo-se do método dedutivo, apontar a importância do preparo e consciência dos médicos para a plena aplicação das Diretivas Antecipadas de Vontade como atos normativos que devem ser respeitados, com a ressalva de que esses profissionais podem deixar de aplicá-las, se as disposições contrariarem o Código de Ética Médica.

\section{MÉTODOS}

O método utilizado na presente pesquisa foi o dedutivo, partindo da premissa geral sobre a intocabilidade do direito à vida para a absorção do instrumento Diretivas Antecipadas de Vontade no Direito, que deve se curvar à oportunização de caminhos que levem ao reconhecimento da dignidade da pessoa humana, no momento final de sua vida.

Sabe-se que a ciência é preciso para a vida humana como forma de compreensão das coisas e os seus fenômenos de modo que a utilização do método dedutivo se torna necessária, onde suas premissas apresentadas proporcionarão uma conclusão pautada na segurança jurídica em caso de sua aplicação (LAKATOS; MARCONI, 2000).

Deste modo, as premissas gerais irão de encontro com o resultado encontrado no último item discorrido, aplicando-se o método dedutivo, observado a partir de uma pesquisa qualitativa.

\section{Diretivas Antecipadas de Vontade}

As diretivas antecipadas de vontade são decisões consubstanciadas por um indivíduo acerca dos tratamentos que desejará ou não se submeter numa situação de terminalidade de vida, em que não conseguirá manifestar a sua vontade. (BARONI, 2021).

Já Dadalto, Tupinambás e Greco (2013, p. 464) complementam que esse instrumento "constitui um gênero de manifestação de vontade para tratamento médico, do qual são espécies o testamento vital e o mandamento duradouro."

Sendo que o testamento vital é quando uma pessoa, no pleno gozo das faculdades mentais redige um documento para nele conter todos os procedimentos, cuidados e tratamentos que deseja submeter-se diante de uma doença que não tenha cura e esteja impossibilitada de manifestar a sua vontade (DADALTO;TUPINAMBÁS; GRECO, 2013). 
Ressalta-se também o testamento vital que acaba por colocar o indivíduo como protagonista de suas relações, momento em que o "testador declara estar inconsciente ou com anomalia psíquica que o torne incapaz de governar a sua pessoa, deseja ou não receber determinados cuidados médicos" (NUNES; MELO, 2011, p. 160).

E o mandamento duradouro é aquela situação em que uma pessoa nomeia outra, que seria o outorgante, cuja responsabilidade é responder diante dos médicos sobre as vontades do outorgado, que estejam exteriorizadas no testamento vital ou verbalizadas, mas desde que respeite todas as suas vontades, pois o outorgado não pode mais manifestar o que deseja (DADALTO; TUPINAMBÁS; GRECO, 2013).

Percebe-se que em ambas as espécies, trata-se de manifestação de vontade diante de uma doença que acometa o estado físico ou mental reconhecidamente incurável e essa manifestação deve ser respeitada.

Essa ideia de manifestação do paciente de seus últimos desejos consubstanciada em um instrumento nasceu nos Estados Unidos em 1967, com a finalidade de resolver os litígios entre "as preferências do paciente a determinados tratamentos em detrimento da vontade ou do entendimento do médico que cuida dele" (BARONI, 2021, p. 259).

Não obstante, foi o advogado Luis Kutner que em 1969 veio a propor o "living will", ou testamento vital, por acreditar que por meio desse documento os desejos do paciente estariam observados e com isso os ditames legais e ético-profissionais estariam respeitados, isentando os médicos de qualquer responsabilização civil e criminal pela eventual morte concretizada. (BARONI, 2021).

Apesar de ser um reconhecimento da autonomia da vontade, existem aqueles que criticam as diretivas antecipadas de vontade por afirmarem que não existe interação entre médico e paciente; pela impossibilidade de predizer o que o paciente desejará diante de um diagnóstico fatal e notadamente de transferir essa vontade para um papel (DADALTO; TUPINAMBÁS; GRECO, 2013, p. 464).

Ainda que existam essas críticas, o que deve ser reconhecido é que com esse instrumento houve a quebra de paradigmas entre médico e paciente e provocou uma releitura na interpretação da autonomia da vontade para o paciente que desejar exteriorizar seus desejos no momento final de sua vida, desde que se cumpram alguns requisitos, conforme estabelecido pelo supracitado advogado Kutner:

O paciente deve deixar expresso a sua vontade em não se submeter a determinados tratamentos caso fique em estado vegetativo ou em qualquer situação de terminalidade de vida, desde que referendado por duas testemunhas; deve entregar esse documento a seu médico pessoal, cônjuge, advogado ou confidente; o Comitê do Hospital onde o paciente se tratar deve referendar esse documento, além da possibilidade de revogação a qualquer tempo antes do paciente chegar ao estado de inconsciência (BARONI, 2021, p. 260).

Esses requisitos foram incorporados pelo Brasil tão somente no campo administrativo, através da Resolução no 1.995 de 2012 do Conselho Federal de Medicina, que define o que venha a ser diretivas antecipadas de vontade como sendo "o conjunto de desejos, prévia e expressamente manifestados pelo paciente, sobre cuidados e tratamentos que quer, ou não, receber no momento em que estiver incapacitado de expressar, livre e autonomamente, sua vontade". (CONSELHO FEDERAL DE MEDICINA, 2012).

Ademais, seu artigo 20 demonstra a vinculação médica à vontade do paciente ou ao seu representante, desde que não fira com os princípios do Código de Ética. E também sobre a revogabilidade, que está ínsito ao documento, haja vista que o paciente pode mudar de ideia ante as novidades terapêuticas que podem surgir até os últimos momentos de sua vida: "é justo, por outro lado, prever a possibilidade de desrespeitá-lo sempre que entre o momento de sua emissão e o momento da decisão final tenham surgido novidades terapêuticas relevantes" (SCHREIBER, 2014, p. 63).

Além de não expor qualquer formalidade extrínseca do documento, a Resolução deixa dúvidas se basta a manifestação de vontade livre no plano existencial ou se faz-se necessário a lavratura de escritura pública pelo Cartório de Notas.

Apesar da divergência, não impera a necessidade do instrumento se consubstanciar em documento público. No entanto, defende-se que se for lavrado em escritura pública, a fé pública atrelada a segurança jurídica é manifesta:
A fé pública decorrente dos atos notariais configura uma segurança 
para a pessoa. Esta fé pública corresponde à confiança que a lei atribui para os atos que o tabelião faz ou declara, quando do exercício da sua função, designando veracidade. Tal atribuição e garantia de segurança jurídica vem com uma severa atribuição de regime de responsabilidade civil, administrativa e penal. E é esta fé pública que dá segurança de veracidade da vontade de alguém quando se formaliza um documento no cartório, podendo ser uma declaração ou um instrumento público. Apesar de se mostrar como a forma mais concreta de comprovação da vontade para elidir possíveis conflitos, a certeza de que a sua vontade será cumprida pelo ato de ter sido feito em cartório, não há. Por exemplo, a única pessoa que tiver conhecimento deste registro pode não o informar à equipe médica e a vontade não ser cumprida, pois não temos um Registro Nacional único, que informe aos hospitais esse anseio. Porém, o registro desta vontade em cartório configura maior segurança ao declarante, no sentido de que podem ser levantadas pretensões diversas por parte de parentes, quando a pessoa não mais puder se manifestar, em relação à veracidade da declaração feita de próprio punho. (CRIPPA; FEIJÓ, 2016, p. 260).

Assim, o registro em cartório também seria um benefício à classe médica, pois ficariam mais resguardados em cumprir a vontade do paciente, sem enfrentar possíveis questionamentos dos familiares insatisfeitos com essa vontade consubstanciada no instrumento.

Ademais, a jurisprudência brasileira, conforme ressalta Anderson Schreiber, já vinha decidindo sobre a isenção de responsabilidade dos médicos que atuem em conformidade com a vontade do paciente:

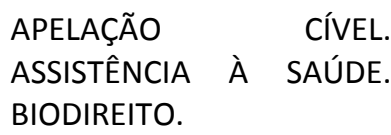
ORTOTANÁSIA.

TESTAMENTO VITAL. 1 . Se o paciente, com o pé esquerdo necrosado, se nega à amputação, preferindo, conforme laudo psicológico, morrer para "aliviar o sofrimento"; e, conforme laudo psiquiátrico, se encontra em pleno gozo das faculdades mentais, o Estado não pode invadir seu corpo e realizar a cirurgia mutilatória contra a sua vontade, mesmo que seja pelo motivo nobre de salvar sua vida. 2. O caso se insere no denominado biodireito, na dimensão da ortotanásia, que vem a ser a morte no seu devido tempo, sem prolongar a vida por meios artificiais, ou além do que seria o processo natural. 3. 0 direito à vida, garantido no art. 5ㅇ, caput, deve ser combinado com o princípio da dignidade da pessoa, previsto no art. 2ㅇ, III, ambos da CF, isto é, vida com dignidade ou razoável qualidade. A Constituição institui o direito à vida, não o dever à vida, razão pela qual não se admite que o paciente seja obrigado a se submeter a tratamento ou cirurgia, máxime quando mutilatória. Ademais, na esfera infraconstitucional, o fato de o art. 15 do CC proibir tratamento médico ou intervenção cirúrgica quando há risco de vida, não quer dizer que, não 
havendo risco, ou mesmo quando para salvar a vida, a pessoa pode ser constrangida a tal. 4. Nas circunstâncias, a fim de preservar o médico de eventual acusação de terceiros, tem-se que o paciente, pelo quanto consta nos autos, fez o denominado testamento vital, que figura na Resolução no 1995/2012, do Conselho Federal de Medicina. 5. Apelação desprovida. (SCHREIBER, 2014, p. 64).

Verifica-se que a todo momento o que o paciente desejar esbarra em sua vontade e no respeito a ela. Por isso, que se defende a exteriorização em cartório para imperar a segurança jurídica ante a lacuna legislativa de tratar sobre o assunto tão relevante.

\section{Autonomia da Vontade Individual}

As ações humanas são objetos de estudos desde a passagem do mito à razão. Os gregos da antiguidade principiaram o conhecimento ocidental acerca do ser, sua origem, sua forma, sua função, formas de interação e sua essência. $O$ foco da investigação existencial passou do deísmo, em que todos os fenômenos derivam da vontade dos deuses, para a atuação do ser humano, como sua autonomia, individual e/ou coletiva. Com a mudança de foco para a racionalidade surge as concepções de direito e de justiça (CASTILHO, 2021).

O direito regula as ações da sociedade cumprindo as funções de compor e prevenir conflitos, bem como, garantir a convivência pacífica, limitando a liberdade individual em prol do coletivo (CAVALIERI FILHO, 2019).

A autonomia individual na atualidade está vinculada ao princípio da liberdade, da pessoa ser capaz de tomar decisões que afetem a sua vida, saúde e especialmente a sua integridade físico-psíquica. Nesse sentido:

O princípio da autonomia está ligado a racionalidade humana de fazer as suas próprias leis. Por isso ele se conecta à prática e à definição das regras sociais, tais como o respeito à privacidade, necessidade de obtenção de permissão para intervir no corpo das pessoas, entre outros. $E$ num sentido mais estrito de dominar racionalmente $o$ mundo e submete-lo as finalidades humanas, por via de desempenho de uma razão subjetiva e independente (BARONI, 2021, p. 269).

Ademais, a legislação vigente dispõe a capacidade do homem de se autodeterminar no meio social, como na Constituição Federal de 1988 que se fundamenta na dignidade da pessoa humana com o objetivo de promover o bem de todos sem preconceitos ou outras formas de discriminação. No Código Civil elencam-se as regras para o exercício da capacidade plena de direito, como a maioridade civil. Ainda, o Decreto no $8.727 / 16$ que garante a autodeterminação do nome social para travestis e transexuais no âmbito da administração pública federal direta, autárquica e fundacional.

Aspectos culturais podem, ainda, garantir ao indivíduo acesso amplo às próprias conviç̧ões, como são os casos do uso de brincos, tatuagens e a circuncisão em ritual religioso, nítidas violações à integridade física.

Os valores são atributos individuais, conforme leciona Reale (2002, p. 30): "cada homem é guiado em sua existência pelo primado de determinado valor, pela supremacia de um foco de estimativa que dá sentido à sua concepção da vida.".

A disposição do próprio corpo é restrita às práticas nocivas à integridade física e à dignidade da pessoa humana. Como exceção, o Código Civil traz como direito de personalidade a possibilidade de dispor o próprio corpo para tratamento médico, em vida, e para estudos científicos, após a morte. Há, ainda, tratativas para transplantes regulamentadas pela Lei $n$ 은 9.434/97. (BRASIL, 1997).

Percebe-se então, que no campo médico a autonomia toca no sentido do paciente informa-se sobre o que é para ele uma necessidade de saúde. Nesse sentido leciona Baroni (2021, p. 271) sobre o direito à autodeterminação pessoal e autonomia: "Todo ser humano adulto e capaz tem o direito a determinar o que é feito com o seu corpo; e um cirurgião que realiza uma intervenção sem o 
consentimento do seu doente comete uma ofensa pelo qual se podem reclamar danos".

Ademais, o filme Admirável Mundo Novo (1980), baseado no livro de mesmo nome do escritor Aldous Huxley (publicado em 1932), retrata uma sociedade futurista estruturada na sistemática fordista de produção em série. (ADMIRÁVEL MUDO NOVO, 1998).

Nessa sociedade há a divisão em castas, proibição do amor, aversão aos relacionamentos monogâmicos, aversão à velhice, os seres humanos são produzidos e programados, encoraja-se a multiplicidade de parceiros sexuais e impõe-se o uso constante da droga "Soma" que provoca uma sensação de constante bem estar. Desde de pequenas, as crianças são ensinadas a não se importarem com a morte, descartando os cadáveres como se fossem peças inúteis em um sistema produtivo.

Resguardando a licença literária e dadas as devidas proporções, referido filme critica a sociedade contemporânea que não se adaptou ao debate sobre o fim da vida, reforçando o obstáculo para respeitar a vontade do falecido.

Autonomia está ligada, portanto, ao exercício da cidadania, uma das bases dos direitos fundamentais do homem atrelada a dignidade da pessoa humana. Na seara médica ganha contornos ainda mais notáveis, pela autonomia do paciente de escolher como será o fim de sua vida.

\section{Autonomia do Paciente e a Intervenção Médica}

Ao se tratar de intervenções médicas, o Código Civil dispõe em seu artigo 15 "Ninguém pode ser constrangido a submeter-se, com risco de vida, a tratamento médico ou a intervenção cirúrgica.". (BRASIL, 2002). Nota-se que o dispositivo atribui ao paciente a decisão definitiva sobre a saúde de seu corpo.

Referente a esse tema, também deve ser enfocado o Enunciado n. 528, da V Jornada de Direito Civil que assim dispõe: "é válida a declaração de vontade expressa em documento autêntico, também chamado "testamento vital", em que a pessoa estabelece disposições sobre o tipo de tratamento de saúde, ou não tratamento, que deseja no caso de se encontrar sem condições de manifestar a sua vontade." (CONSELHO DA JUSTIÇA FEDERAL, 2011).

Por seu turno, o profissional médico possui o dever de guardar absoluto respeito pelo ser humano e atuar sempre em seu benefício, mesmo depois da morte, conforme preconiza o Código de Ética Médica, Capítulo I, inciso VI. (CONSELHO FEDERAL DE MEDICINA, 2009).

Ainda, o referido código em seu artigo 31 veda ao médico desrespeitar o direito do paciente ou de seu representante legal de decidir livremente sobre a execução de práticas diagnósticas ou terapêuticas, salvo em caso de iminente risco de morte. Dispondo as conviç̧ões das partes em possível conflito. (CONSELHO FEDERAL DE MEDICINA, 2009).

Como se não bastasse, o artigo 9ㅇ da Convenção sobre os Direitos do Homem e a Biomedicina de 1997, ratificada no Brasil pela Resolução no 01 de 2001, prevê que: "a vontade anteriormente manifestada no tocante a uma intervenção médica por um paciente que, no momento da intervenção não se encontre em condições de expressar a sua vontade, será tomada em conta". (DIÁRIO DA REPÚBLICA ELETRÔNICO, 2001).

Assim, a sociedade contemporânea progride ao sentido de efetivar o princípio de liberdade individual em sua plenitude, qual seja, numa visão prospectiva. Isso porque os percalços conflituosos expõem a necessidade de avaliações filosóficas, sociais e acadêmicas, para que haja pacificação quanto à temática contraposta na relação médico e paciente.

É o que será exposto nos comentários a seguir do Filme Mar Adentro, pois se fosse assegurado ao espanhol Ramón a liberdade e autonomia sobre a sua vida, seguramente teria tido uma morte digna.

\section{Breviário do filme Mar Adentro}

Mar adentro é um filme, lançado no ano de 2004 e premiado pelo Oscar na categoria de melhor filme estrangeiro.

A narrativa, dirigida por Alejandro Amenábar, confronta o direito à vida versus o direito de morrer, com fulcro na história verídica de Ramón Sampedro, tetraplégico aos 25 anos, que permaneceu nessa situação por três décadas e se tornou um modelo de luta após o trágico acidente sofrido, no qual, o leva a peticionar pelo direito de morrer com dignidade, pois, seu tratamento tornou-se doloroso e incurável, e que teve seu pedido negado pela justiça, pois a lei espanhola considerava $\mathrm{O}$ ato como homicídio (QUARESMA, 2009).

O filme leva à reflexão acerca da liberdade enfeixada com a dignidade, pois o espanhol que era marinheiro ativo não gostaria 
de ter permanecido nessa situação penosa por quase 28 anos: "eu quero morrer porque a vida para mim nesse estado.... A vida assim não é digna. Entendo que os outros tetraplégicos possam se ofender quando eu digo que a vida assim é indigna" (QUARESMA, 2009).

Ademais, mesmo os familiares de Ramón, como o seu irmão que rechaçava a possibilidade da eutanásia, o pai que sofria calado pela infelicidade de seu filho, ressalta-se novamente a mensagem trazida pelo filme sobre a importância de respeitar os desígnios de Ramón, que levou a se suicidar com a ajuda de sua namorada, ante a negativa de realizar a eutanásia.

A eutanásia advém do grego que significa boa morte ou morte digna. Advém de eu: que significa bem, pleno, bem e thanasia que significa morte. Seria um ato intencional de proporcionar ao paciente uma morte indolor ante a uma doença incurável pelo qual o paciente esteja sofrendo. É realizado por um profissional médico mediante pedido expresso, cujos motivos resumem-se em dores intensas ou insuportáveis aliadas a não qualidade de vida (ROCHA, 2014).

Por isso que a eutanásia pode ser voluntária quando o doente que deseja morrer e se expressa nesse sentido e a involuntária quando outra pessoa decide por ele, e cumpre o desejo já manifestado do paciente. E também ativa quando o médico abrevia a vida do paciente e passiva quando deixa o paciente morrer, não prolongamento artificialmente a vida desse doente (ROCHA, 2014).

Irrelevante a eutanásia ocorrer de forma voluntária ou involuntária ou ativa ou passiva, o que é certo é que o agente causador responderá, pelo ordenamento jurídico brasileiro, como crime de homicídio, tipificado no artigo 121 do Código Penal. (BRASIL, 1940).

Difere do suicídio assistido, haja vista que a morte ocorre pela conduta do próprio paciente, que por ser portador de uma doença incurável não quer prolongar o seu sofrimento. Nesse caso, o agente, que pode ser qualquer pessoa que auxilie ou assista a prática do suicídio responde pelo crime de induzimento, instigação ou auxílio ao suicídio, tipificado no artigo 122 do Código Penal (BRASIL, 1940).

No filme, o que ocorreu foi o suicídio assistido pela namorada do protagonista, o que imprime a mensagem que o dever dos médicos não se restringe a adoção de cuidados paliativos aos doentes e estendendo aos familiares, mas sobretudo de se respeitar a vontade exteriorizada por esse paciente, que faz jus a seu conceito de morte digna.

\section{CONSIDERAÇÕES FINAIS}

O presente estudo teve como objetivo ressaltar a importância das Diretivas Antecipadas de Vontade diante da inexistência da legislação sobre o assunto. Isso porque mostrou-se relevante a tutela dos últimos momentos da vida da pessoa como corolário da autonomia da vontade enfeixado com a dignidade da pessoa humana.

Por isso trouxe o reconhecimento desse instrumento que proporcionará ao paciente que o respeito a sua liberdade e autonomia sobre os tratamentos que deseja ou não se submeter ante a uma situação de doença incurável, e também aos médicos que não responderão civil ou criminalmente na justiça.

Para tanto, defendeu-se que as diretivas devem se consubstanciar em instrumento público por imprimir segurança jurídica aos profissionais de saúde.

Ressalva-se que os limites que o médico terá com o seu paciente está pautado no Código de Ética, haja vista a disposição expressa a autonomia do paciente, desde que não fira com as suas disposições.

Também se enfatizou que esse documento pode ser modificado e revogado ao longo da vida do paciente, caso mude de opinião em decorrência de suas crenças ou de outras respostas terapêuticas que possam surgir.

Assim, diante de toda a discussão travada no trabalho, o direito à morte digna deve ser respeitado, conforme deveria ter ocorrido na situação fática do filme Mar Adentro, o que passa a ser um desafio para o operador do direito, que deve resguardar e primar pelas ingerências negativas que pendem no ser humano, com a sensibilidade exigida dos avanços da medicina nesse tema.

\section{REFERÊNCIAS}

ADIMRÁVEL MUNDO NOVO. Filme Admirável Mundo Novo. Título Original: Brave New Word, $1998 . \quad$ Disponível em: https://www.adorocinema.com/filmes/filme137145/. Acesso em: 09 jul. 2021.

BARONI, M.S. As diretivas antecipadas de vontade como instrumento de efetivação da autonomia privada do indivíduo, In. ALVIM, A.; MELLO, C.; RODRIGUES, D. C; ALVIM, T (org.). Direito Médico. Aspectos Materiais, Éticos e 
Processuais. 1. ed. São Paulo: Thomson Reuters Brasil, 2021. p. 257-281.

BRASIL. Constituição (1988). Constituição da República Federativa do Brasil. Brasília, DF: Senado Federal: Centro Gráfico, 1988. Disponível em:

http://www.planalto.gov.br/ccivil_03/leis/19434.

htm. Acesso em: 09 jul. 2021.

BRASIL. Decreto-Lei no 2.848, de 07 de dezembro de 1940. Institui o Código Penal. Diário Oficial da União, Rio de Janeiro, $31 \mathrm{dez}$. 1940. Disponível em:

http://www.planalto.gov.br/ccivil_03/decretolei/del2848compilado.htm. Acesso em: 09 jul. 2021.

BRASIL. Lei no 9. 434, de 04 de fevereiro de 1997. Dispõe sobre a remoção de órgãos, tecidos e partes do corpo humano para fins de transplante e tratamento e dá outras providências. Disponível em:

http://www.planalto.gov.br/ccivil_03/_ato20152018/2016/decreto/d8727.htm. Acesso em 09 jul. 2021.

BRASIL. Lei no 10.406, de 10 de janeiro de 2002. Institui o Código Civil. Disponível em: http://www.planalto.gov.br/ccivil_03/leis/2002/I 10406compilada.htm. Acesso em: 09 jul. 2021.

BRASIL. Decreto n. 8727, de 28 de abril de 2016. Dispõe sobre $o$ uso do nome social e o reconhecimento da identidade de gênero de pessoas travestis e transexuais no âmbito da administração pública federal direta, autárquica e fundacional. Disponível em: http://www.planalto.gov.br/ccivil_03/_ato20152018/2016/decreto/d8727.htm. Acesso em: 09 jul. 2021.

BRASIL. Código de Ética Médica. Resolução CFM $n^{\circ} \mathbf{2 . 2 1 7}$, de 27 de setembro de 2018, modificada pelas Resoluções CFM no 2.222/2018 e 2.226/2019. Disponível em: https://portal.cfm.org.br/images/PDF/cem2019.p df. Acesso em: 15 jul. 2021.

CASTILHO, R. D. S. Filosofia Geral e Jurídica. 7. ed. São Paulo: Saraiva, 2021.

CAVALIERI FILHO, S. Programa de Sociologia Jurídica. São Paulo: Grupo GEN, 2019.
CRIPPA, A.; FEIJÓ, A. M. G. S. O registro das Diretivas Antecipadas de Vontade: opinião dos tabeliães da cidade de Porto Alegre-RS. Revista Bioética no Mundo da Saúde, São Paulo,; v. 40, n. 2, p. 257-266, 2016. https://doi.org/10.15343/0104-

7809.20164002257266

CONSELHO DA JUSTIÇA FEDERAL. V Jornada de Direito Civil. Enunciado n. 528. Disponível em: https://www.cjf.jus.br/enunciados/enunciado/59 7. Acesso em: 03 ago. 2021.

CONSELHO FEDERAL DE MEDICINA. Resolução CFM 1.931, de 17 de setembro de 2009. Dispõe sobre o Código de Ética Médica. Disponível em: https://portal.cfm.org.br/images/stories/bibliote ca/codigo\%20de\%20etica\%20medica.pdf. Acesso em: 02 ago. 2021.

CONSELHO FEDERAL DE MEDICINA. Resolução CFM 1.995, de 31 de agosto de 2012. Dispõe sobre as diretivas antecipadas de vontade dos pacientes. 2012. Disponível em: https://www.legisweb.com.br/legislacao/?id=244 750. Acesso em: 02 ago. 2021.

DADALTO, L; TUPINAMBÁS, U; GRECO, D. B. Diretivas antecipadas de vontade: um modelo brasileiro. Revista Bioética (Impr.),v. 21, p. 46376, 2013. https:. //doi.org/10.1590/S1983$\underline{80422013000300011}$

DIÁRIO DA REPÚBLICA ELETRÔNICO. Resolução da Assembleia da República no 01/ 2021. Disponível em: https://dre.pt/pesquisa//search/235128/details/maximized. Acesso em: 03 ago. 2021.

LAKATOS, E. M.; MARCONI, M. A. Metodologia científica. 3. ed. São Paulo: Atlas, 2000.

NUNES, R.; MELO, H. P. Testamento Vital. Coimbra: Almedina, 2011.

QUARESMA, H. H. A análise do filme Mar Adentro e o instituto da Eutanásia. Disponível em:

https://www.jurisway.org.br/v2/dhall.asp?id_dh= 3366. Acesso em: 03 ago. 2021.

REALE, M. Introdução à Filosofia. 4. ed. São Paulo: Saraiva, 2002. 
ROCHA, R. Eutanásia, Suicídio Assistido, Distanásia, Ortotanásia e Testamento Vital: Aspectos Éticos e Jurídicos Acerca da Morte Digna. Revista Eletrônica de Ciências Jurídicas e Sociais da Universidade Cruzeiro Do Sul, São Paulo, v. 1, n. 3, jan./jun. 2014.

SCHREIBER, A. Direitos da Personalidade. 3. ed. rev. atual. São Paulo: Atlas, 2014. 